\title{
Identificación de fármacos reguladores de la actividad del promotor Egr-1 en fibroblastos humanos transducidos con Ad $\Delta$ egr-1-Luc7
}

\author{
Identification of drugs as regulators on the activity of Egr-1 promoter in human \\ fibroblasts transduced with Ad $\Delta$ egr-1-Luc7
}

\begin{abstract}
Francisco Martínez-Flores ${ }^{1-3 *}$, Hugo Sandoval', Elizabeth Arce de la Vega', Ricardo J. García-Cavazos², Fausto A. Jiménez-Orozco ${ }^{3}$, Margarita Valdes-Flores ${ }^{4}$ y Juan A. Madinaveitia-Villanueva ${ }^{4}$

${ }^{1}$ Programa de Bioterapéutica Molecular, Banco de Piel y Tejidos, Instituto Nacional de Rehabilitación Luis Guillermo Ibarra Ibarra, Secretaría de Salud; '2Departamento de Genética, Hospital General de México, Secretaría de Salud; ${ }^{3}$ Departamento de Farmacología, Facultad de Medicina, Universidad Nacional Autónoma de México; ${ }^{4}$ Instituto Nacional de Rehabilitación Luis Guillermo Ibarra Ibarra, Secretaría de Salud. Ciudad de México, México
\end{abstract}

\begin{abstract}
Resumen
Introducción: La proteína de respuesta temprana a crecimiento 1 (EGR-1) es un factor de transcripción involucrado en la diferenciación y la proliferación celulares, cuya expresión es regulada por su promotor en respuesta a diversos factores físicos y químicos, y a fármacos. Aquí se describen algunos de los principales efectos de los fármacos esteroides y del factor de crecimiento epitelial 1 (EGF-1) sobre la actividad del promotor, mediante un sistema reportero transducido por el adenovirus Addegr-1-Luc7 en fibroblastos primarios humanos. Método: Los fibroblastos primarios humanos fueron cultivados en pase 5, transducidos con Adsegr-1-Luc7 y expuestos a betametasona, hidrocortisona, dexametasona, testosterona, beta-estradiol y EGF-1 durante 1, 3 y 6 horas. La actividad de reportero fue cuantificada por luminometría y ajustada a la concentración de proteínas totales. Resultados: La actividad del promotor en presencia de betametasona, hidrocortisona, dexametasona, testosterona y beta-estradiol fue similar a la actividad basal del promotor a las 1, 3 y 6 horas. El control positivo mostró una actividad 17.8 veces mayor a las 6 horas $(p \leq 0.05)$. De manera similar, las células expuestas a EGF-1 mostraron una actividad 22.07 veces mayor que las células sin fármaco. Conclusión: La actividad del promotor Egr-1 en fibroblastos humanos es regulada negativamente por los fármacos esteroides y positivamente por el EGF-1.
\end{abstract}

PALABRAS CLAVE: Promotor Egr-1. Esteroides. Adenovirus. Fibroblastos humanos. EGF-1. Terapia génica.

\begin{abstract}
Introduction: The early growth response protein (EGR-1) is a transcription factor involved in cell differentiation and proliferation, whose expression is regulated by its promoter in response to various physical, chemical and drug factors. Hereby, we describe some of the main effects of steroid drugs and EGF-1 on promoter activity, through a reporter system transduced by Addegr-1-Luc7 in human primary fibroblasts (HPF). Methods: Human primary fibroblasts transduced with AdDegr-1-Luc7 were exposed to betamethasone, hydrocortisone, dexamethasone, testosterone, beta-estradiol, and EGF-1 during 1, 3 and $6 \mathrm{~h}$. Reporter assay was quantified by luminometry. Results: The activity of the promoter in presence of betamethasone, hydrocortisone, dexamethasone, testosterone and beta-estradiol were similar to the basal activity of the promoter at 1, 3 and $6 \mathrm{~h}$. The positive control showed an activity 17.8 folds higher $(p \leq 0.05)$ at 6 h. EGF-1 showed activity of 22.07 folds greater than
\end{abstract}

\footnotetext{
Correspondencia:

*Francisco Martínez Flores

Calzada México-Xochimilco 289

Col. Arenal de Guadalupe

C.P. 14389, Ciudad de México, México

E-mail: fcomartinef@comunidad.unam.mx
}

Fecha de recepción: 28-02-2018

Fecha de aceptación: 25-04-2018

DOI: 10.24875/CIRU.M18000045
Cir Cir. 2018;86:228-236

Contents available at PubMed www.cirugiaycirujanos.com 
cells without drug. Conclusion: The activity of the EGR-1 promoter in human fibroblasts is negatively regulated by steroid drugs and positively by the EGF-1.

KEY WORDS: EGR-1 promoter. Steroids. Adenovirus. Human fibroblasts. EGF-1. Gene therapy.

\section{Introducción}

La proteína de respuesta temprana a crecimiento (EGR-1) es un factor de transcripción involucrado en la activación de vías mitogénicas y en la diferenciación celular en tejidos embrionarios, pulmón, tejido articular, fibroblastos de la piel y células tumorales de gliomas y leucemias ${ }^{1-5}$. La expresión de EGR-1 es regulada esencialmente por la región promotora del gen a diferentes inductores, entre los cuales se encuentran factores como la temperatura, los cambios osmóticos y osmolares, la presión, la hipoxia, la luz ultravioleta (UV), la radiación gamma, y la estimulación de la actividad transcripcional del factor de crecimiento tumoral beta y de proteínas involucradas en la vía de la síntesis de colágena ${ }^{6-10}$.

El mecanismo específico para la regulación de la actividad transcripcional del promotor se realiza mediante secuencias de unión responsivas al AMP cíclico (CRE), elementos de respuesta al suero o a través de los sitios de unión de la proteína EGR-1 (EBS) como un mecanismo de autorregulación negativa y que se encuentran en los primeros 600 pares de base corriente arriba del sitio de inicio de la transcripción (caja TATA) $)^{11-15}$.

El efecto mitogénico de la proteína EGR-1 es mediado por su plegamiento en dedos de zinc que reconocen secuencias consenso (CCGG/TGGGCCG) en el promotor de varios genes y que, además, le confiere un mecanismo de autorregulación a través del sitio de unión sobre su propio promotor (EBS) ${ }^{16,17}$.

Los glucocorticoides naturales y sintéticos son moléculas con actividad pleiotrópica, cuyo mecanismo de acción es mediado por receptores citoplasmáticos que translocan al núcleo y activan secuencias responsivas a glucocorticoides ${ }^{18}$. Una vez en el núcleo, el complejo droga-receptor se une a secuencias (5'AGAACANNNTGTTCT-3') de promotores que regulan la actividad de las proteínas cinasas o de las proteínas involucradas en las vías de señalización mitogénicas (Fos, Jun y Egr-1), así como de las cinasas activadoras de mitógenos (MAP-cinasas, ERK y ELK) $)^{19,20}$.

Los fármacos esteroides representan uno de los elementos terapéuticos esenciales para regular los procesos inflamatorios sistémicos y locales; sin embargo, no se conocen totalmente sus efectos sobre la actividad de los promotores, como en el caso de la EGR-1 en los fibroblastos de la piel|21-23.

Aquí se reportan los efectos de fármacos derivados esteroideos (dexametasona, hidrocortisona, betametasona), hormonas esteroides como el beta-estradiol y la testosterona, y del factor de crecimiento epitelial 1 (EGF-1), con el objetivo de identificar reguladores farmacológicos (negativos o positivos) sobre el promotor de la proteína EGR-1.

\section{Método}

\section{Obtención de fibroblastos primarios humanos}

Los ensayos experimentales descritos en este artículo se derivan del protocolo de investigación con número de registro INR-CII-14B-2011, autorizado por el Comité Interno de Investigación del Instituto Nacional de Rehabilitación Luis Guillermo Ibarra Ibarra. Los fibroblastos primarios humanos (FPH) fueron obtenidos del Banco de Piel y Tejidos del mismo Instituto, de acuerdo con el protocolo estandarizado (PR-DQ17- ISO-9001- 2008). Brevemente, los FPH fueron aislados a partir de aloinjertos de dermis de grosor medio obtenidos de donantes multiorgánicos y sometidos a disgregación enzimática con colagenasa al $1 \%$ en solución amortiguadora de fosfatos modificada de Dulbecco (D-PBS) durante 1 hora. Inmediatamente se centrifugaron a $1000 \mathrm{G}$ durante 10 minutos a $4{ }^{\circ} \mathrm{C}$ y se lavaron con medio esencial mínimo modificado de Dulbecco (D-MEM) suplementado con antibióticos y suero fetal bovino inactivado por calor (SFB) (Gibco-Invitrogen Corp.). Posteriormente, las células obtenidas fueron sembradas en cajas de $10 \mathrm{~cm}$ de diámetro en presencia de medio D-MEM suplementado con un 10\% de SFB y antibiótico antimicótico a concentraciones estandarizadas (penicilina G, estreptomicina y anfotericina B).

\section{Cultivo de fibroblastos primarios humanos}

Las células de FPH se cultivaron en medio D-MEM con un $10 \%$ de SFB y $5 \mathrm{mM}$ de ácido ascórbico en un ambiente con el $5 \%$ de $\mathrm{CO}_{2}$, el $20 \%$ de $\mathrm{O}_{2}$ y el $100 \%$ de humedad a $37{ }^{\circ} \mathrm{C}$, hasta alcanzar una 

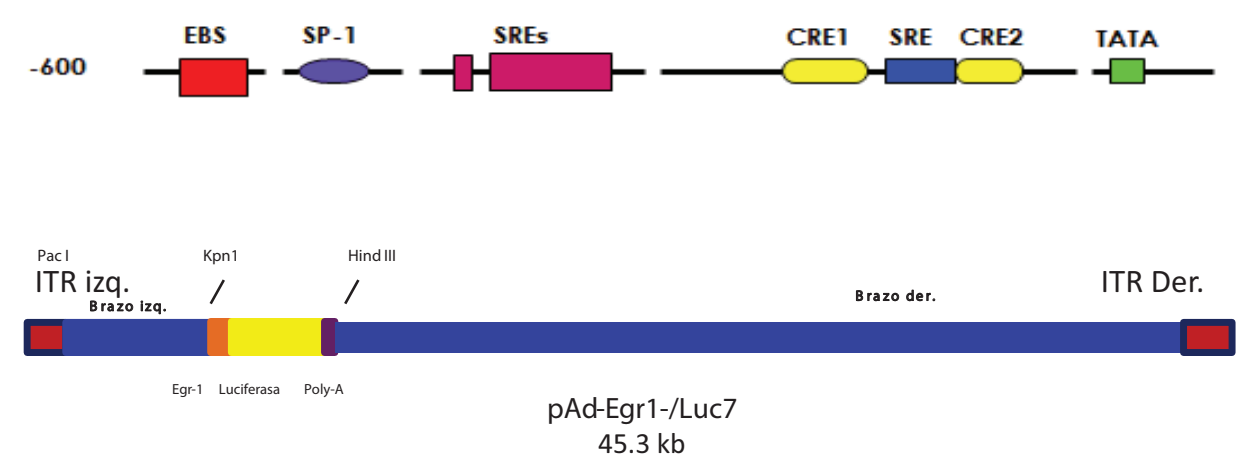

Figura 1. Estructura del adenovirus recombinante no replicativo Ad-Egr-1-Luc7. Diagrama que ilustra la incorporación del casete reportero en el vector adenoviral no replicativo. Los 600 pb del promotor EGR-1 fueron clonados corriente arriba de la secuencia del gen de la luciferasa como reporteros.

confluencia del $80 \%$ en cajas de cultivo T-75 cubiertas con colágena (GrainerBioOne, Corp., Alemania). Las células se disgregaron y fueron resembradas hasta el pase 5. Posteriormente fueron criopreservadas en nitrógeno líquido hasta la realización de los ensayos de inducción con fármacos.

\section{Modelo experimental para la inducción con fármacos}

El sistema de evaluación y análisis del efecto de inducción farmacológica sobre el promotor está basado en un sistema reportero, transducido por un adenovirus no replicativo de tercera generación $(\operatorname{Ad} \Delta 3)$. Las células fueron cultivadas e infectadas con un adenovirus recombinante no replicativo que transduce el casete del promotor Egr-1, para dirigir la expresión del gen de la luciferasa clonado en el Ad-egr-1-Luc7 (Fig. 1). La luciferasa es una enzima expresada en lampíridos (insecta-coleóptera) que hidroliza la luciferina en presencia de ATP y cuya emisión de luz puede ser cuantificada en un detector lumínico. Las cuentas lumínicas son dependientes de la concentración de la proteína en un extracto celular total de las células expuestas. A su vez, el incremento o la disminución de la concentración de la luciferasa es resultante de la regulación negativa o positiva del promotor en presencia de los diferentes fármacos (Fig. 1).

\section{Producción a gran escala del adenovirus recombinante Ad-Egr1/Luc7 y AdCMV-hGFP}

Los inóculos de cada virus fueron empaquetados en células HEK-293 (Invitrogen Corporation-AATC, EE.UU.) y purificados a gran escala para aplicaciones in vivo a partir de 250 millones de células HEK-293, en medio D-MEM/F12 (50:50) con 5 mM de L-glutamina y un $10 \%$ de SFB inactivado por calor y esterilizado por filtración (Thermo-Hyclone Corp., EE.UU.). Al término del tiempo de infección, las células empaquetadoras se mantuvieron en condiciones de cultivo habitual para la maduración de los viriones y se monitorizaron por microscopía óptica hasta la aparición de efecto citopático del $90 \%$, que ocurrió a las 48 horas tras la infección (Fig. 2).

Posteriormente las células fueron colectadas, concentradas y lisadas por tres ciclos de choque térmico en nitrógeno líquido alternado a temperatura de $37^{\circ} \mathrm{C}$ durante 3 minutos, respectivamente, en campana de flujo laminar de clase II-AB, para la purificación de los viriones recombinantes.

\section{Purificación de los vectores adenovirales no replicativos}

Con objeto de separar los viriones maduros de los inmaduros, así como los restos celulares, los lisados totales fueron mantenidos en frío y purificados por ultracentrifugación en gradientes de cloruro de cesio a $28,000 \mathrm{G}$, a $4{ }^{\circ} \mathrm{C}$ durante 12 horas (WX-100 Thermo Corp., EE.UU.). Posteriormente, los viriones se aislaron por punción estéril y se dializaron (en presencia de magnesio y de $5 \mathrm{mM}$ de HEPES a $4{ }^{\circ} \mathrm{C}$ durante $12 \mathrm{~h}$ ) en un casete con membrana de 10,000 MWCO (Pierce Bioscience, EE.UU.). Los viriones recombinantes purificados se diluyeron en solución de preservación viral (1\% de albúmina y $5 \mathrm{mM}$ de HEPES y $\mathrm{Mg}^{++}$) y fueron almacenados a $-70{ }^{\circ} \mathrm{C}$. La eficiencia de la infectividad y la titulación de las partículas virales infectantes se determinó por ensayo de placa en monocapas de células HEK-293 a diluciones seriadas 


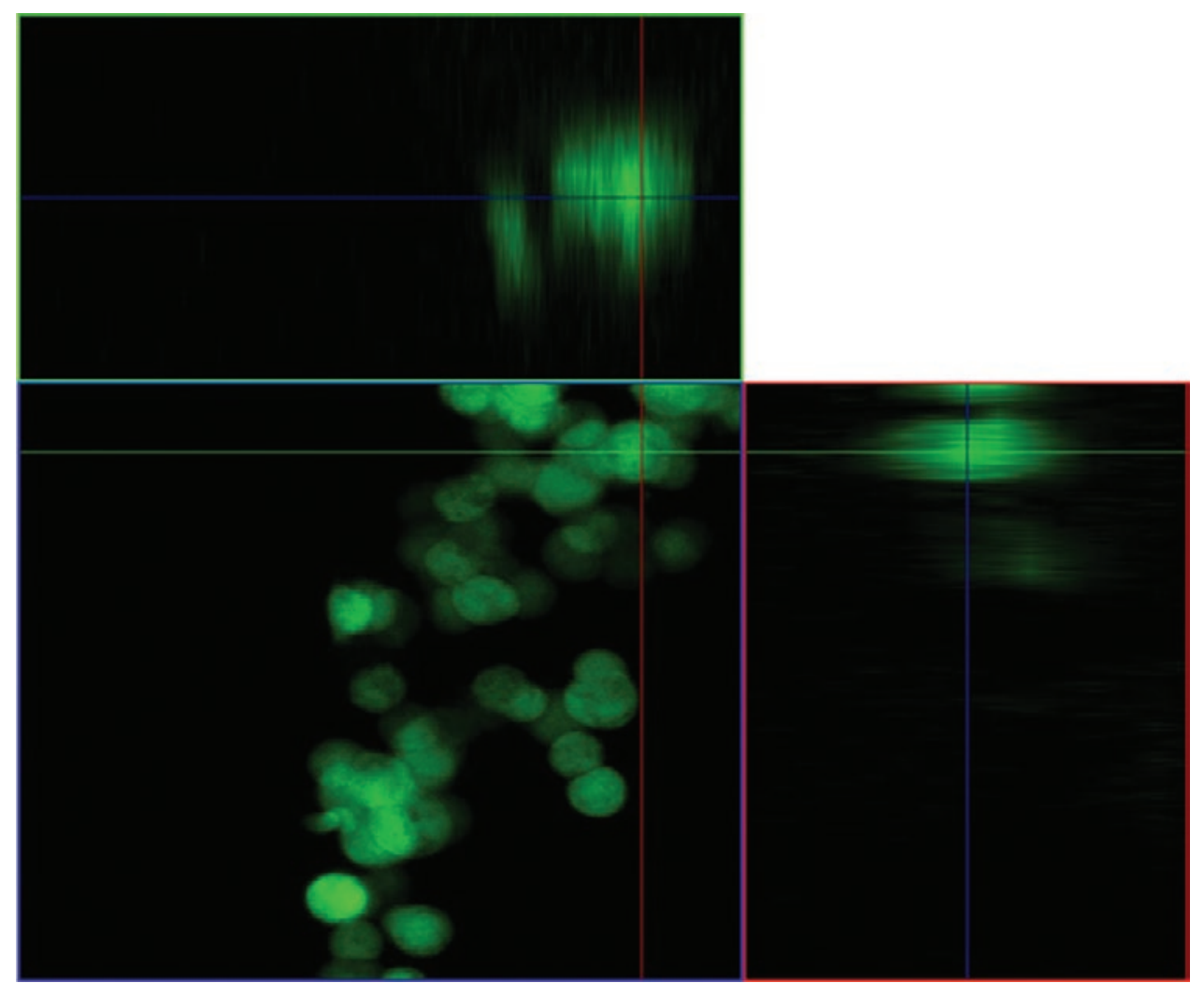

Figura 2. Maduración de viriones Ad CMV-hGFP. La células HEK-293 fueron transfectadas y posteriormente infectadas para producción a gran escala con objeto de determinar el proceso de maduración de los diferentes viriones generados a las 48 horas y documentados mediante microscopía confocal láser a $488 \mathrm{~nm}$.

$\left(10^{-6}, 10^{-7}, 10^{-8}, 10^{-9}, 10^{-10}, 10^{-11}\right)$, así como por lectura de la densidad óptica del dializado a $260 \mathrm{~nm}$.

\section{Infección y determinación del múltiplo de infección óptimo en fibroblastos primarios humanos con el adenovirus Ad-CMV-hGFP}

Para determinar la cantidad óptima de adenovirus recombinante necesaria para la transducción eficiente de los FPH se usó un adenovirus AdCMV-hGFP que expresa la proteína verde fluorescente humanizada. Para ello, se sembraron $3 \times 10^{5}$ células en cajas de seis pozos (Costar, Madison, EE.UU.). Pasadas 24 horas, las células fueron infectadas con 25, 50, 75, 100 y 200 múltiplos de infección óptimos (MOI) con el adenovirus reportero $A d-C M V$ - $h$ GFP en medio reducido en suero. Al término de 2 horas de exposición, el medio infectante fue reemplazado por medio fresco y las células transducidas se mantuvieron en cultivo por 24 horas. Para documentar la eficiencia de la infección, se buscó la señal de la GFP usando un equipo Axioplan 2 (Carl Zeiss, Alemania). La GFP emitió una señal luminosa excitable a $488 \mathrm{~nm}$ en las células infectadas por el adenovirus Ad-CMV-hGFP.

\section{Identificación de la proteína EGR-1 en fibroblastos humanos}

La colocalización de la proteína EGR-1 se realizó por inmunofluorescencia y fue documentada por microscopía confocal láser. Para este ensayo se sembraron 1 $\times 10^{7} \mathrm{FPH}$ en una cámara de cultivo con fines de microscopía (Slide-chamber Nunc Corp., EE.UU.) en medio D-MEM con un $2 \%$ de SFB. Las células fueron expuestas a luz UV durante 30 segundos, fijadas en PBS y un $1 \%$ de glutaraldehído durante 10 minutos a $4^{\circ} \mathrm{C}$. Las laminillas se permeabilizaron con solución amortiguadora salina de fosfatos con un $1 \%$ de Tween 20 (TBS) durante 15 minutos, seguido de 4 horas de bloqueo a $4{ }^{\circ} \mathrm{C}$ con $100 \mathrm{mM}$ de glicina en TBS. La incubación con el anticuerpo primario se realizó en TBS al $0.5 \%$ y un $1 \%$ de albúmina con una dilución de 1:100 del anticuerpo IgG anti-EGR-1 humano desarrollado en conejo (Santacruz, Biotech). Un anticuerpo secundario anticonejo desarrollado en ratón y acoplado a PE-Cy7 fue usado a la dilución recomendada por el fabricante e incubado por 2 horas a $4{ }^{\circ} \mathrm{C}$. Las laminillas fueron lavadas y cubiertas con medio de montaje Vecta Shield (Santacruz, Biotech) para su análisis a 
$630 \mathrm{~nm}$ por microscopía confocal láser en un equipo LSM-100 Meta (Carl Zeiss, Alemania).

\section{Ensayo reportero de luciferasa inducido por fármacos}

Se sembraron $3 \times 10^{5} \mathrm{FPH}$ en una caja de seis pozos en condiciones de cultivo estándar hasta su adherencia. Transcurridas 12 horas, el medio fue reemplazado con un $1 \%$ de SFB para reducir la actividad del promotor EGR-1 endógeno a valores basales durante las siguientes 24 horas. Al término de este tiempo, el medio fue reemplazado por medio D-MEM (Gibco-Invitrogen Corp., EE.UU.) con fármacos a las siguientes concentraciones: testosterona $25 \mathrm{ng} / \mathrm{ml}$, beta-estradiol $50 \mathrm{ng} / \mathrm{ml}$, hidrocortisona $50 \mathrm{ng} / \mathrm{ml}$, betametasona $50 \mathrm{ng} / \mathrm{ml}$; y por EGF-l a una concentración de $50 \mathrm{ng} / \mathrm{ml}$, todos durante 1,3 y 6 horas. Al término de cada tiempo, las células fueron lisadas para la extracción de proteínas y análisis de luminometría.

\section{Extracción de proteínas totales}

La extracción de proteínas totales de las células expuestas a diferentes fármacos se realizó de la siguiente manera: al término del tiempo de exposición ( 1,3 y 6 h) las células se lavaron con PBS (con $\mathrm{Ca}^{++}$ y $\mathrm{Mg}^{+}$) (Invitrogen Corp.) a $37{ }^{\circ} \mathrm{C}$ y se lisaron con $300 \mu \mathrm{l}$ de solución de lisis (Glo-Cell lisis Buffer, Promega Corp., EE.UU.) a temperatura ambiente por 5 minutos. El lisado fue colectado en un microtubo estéril, agitado por 1 minuto e inmediatamente centrifugado a $5000 \mathrm{G}$ a $4{ }^{\circ} \mathrm{C}$. El sobrenadante fue recuperado y almacenado a $-20{ }^{\circ} \mathrm{C}$ hasta su lectura en un cuantificador de luminometría.

\section{Cuantificación de la actividad luciferasa}

Los ensayos de luminometría se realizaron con $50 \mu \mathrm{l}$ del lisado celular, con una relación de 1:1 volúmenes de sustrato Glo-Luciferase (Promega, EE.UU.). La mezcla se incubó durante 10 minutos a $23^{\circ} \mathrm{C}$ e inmediatamente la reacción fue cuantificada en un luminómetro (DTX-800 Beckman Coulter). La luciferasa presente en el extracto proteico hidroliza a la luciferina en presencia de ATP, generando una señal luminosa identificada por el lector y expresada en cuentas lumínicas por segundo (CL/s). Las CL/s se ajustaron a la concentración de proteínas para obtener los datos reales de actividad de luciferasa controlada por el promotor Egr-1. El análisis de las $\mathrm{CL} / \mathrm{s}$ se realizó con el programa Multimode Analysis Software (Beckman Coulter, EE.UU.).

\section{Resultados}

La determinación del MOI para transducir de manera eficiente a los FPH fue determinada con el adenovirus reportero Ad-CMV-hGFP. Los datos obtenidos indicaron que el uso de un $\mathrm{MOI}$ de 75 es suficiente para transducir de manera episomal el casete de interés a los FPH de manera eficiente, sin producir efecto citopático (datos no mostrados).

Previamente se realizó la tipificación de las células obtenidas y cultivadas in vitro con la inmunolocalización de proteínas marcadoras como actina 1 y colágena I como marcadores de superficie (datos no mostrados). Este proceso se realiza de manera sistemática para caracterizar las células obtenidas de donantes de aloinjertos de piel.

Para determinar la expresión endógena de la proteína EGR-1 se realizaron ensayos de inducción para sobreexpresar la proteína. Estos ensayos se realizaron con la exposición de las células FPH a luz UV durante 30 segundos y procesada para para la inmunolocalización, mostrando una localización citoplasmática y nuclear de la proteína EGR-1 (Fig. 3).

\section{Efecto de los fármacos esteroides sobre el promotor Egr-1 en fibroblastos primarios humanos}

Los FPH transducidos con Ad-Egr-1Luc7+ mostraron una actividad basal de luciferasa con 1,478.33, 1340.66 y $1333.36 \mathrm{CL} / \mathrm{s}$ a las 1,3 y 6 horas, respectivamente. Tal como se esperaba, no se encontró actividad lumínica en las células no transducidas, debido a que la luciferasa no se expresa en células humanas (Fig. 4).

Los efectos de la betametasona, la hidrocortisona, la testosterona y el beta-estradiol fueron bajos en comparación con las células control (FPH con $2 \%$ de SFB), que mostraron una actividad de $175 \mathrm{CL} / \mathrm{s}$ por microgramo de proteínas totales.

La hidrocortisona tuvo un efecto negativo sobre la actividad del promotor. Las cuentas lumínicas obtenidas fueron de $781.66,1433.66$ y $1782.66 \mathrm{CL} / \mathrm{s}$ a las 1 , 3 y 6 horas, respectivamente. La betametasona mostró una actividad de 1254.33, 1572 y $4419.33 \mathrm{CL} / \mathrm{s}$ a las 1, 3 y 6 horas, respectivamente; y el beta-estradiol 


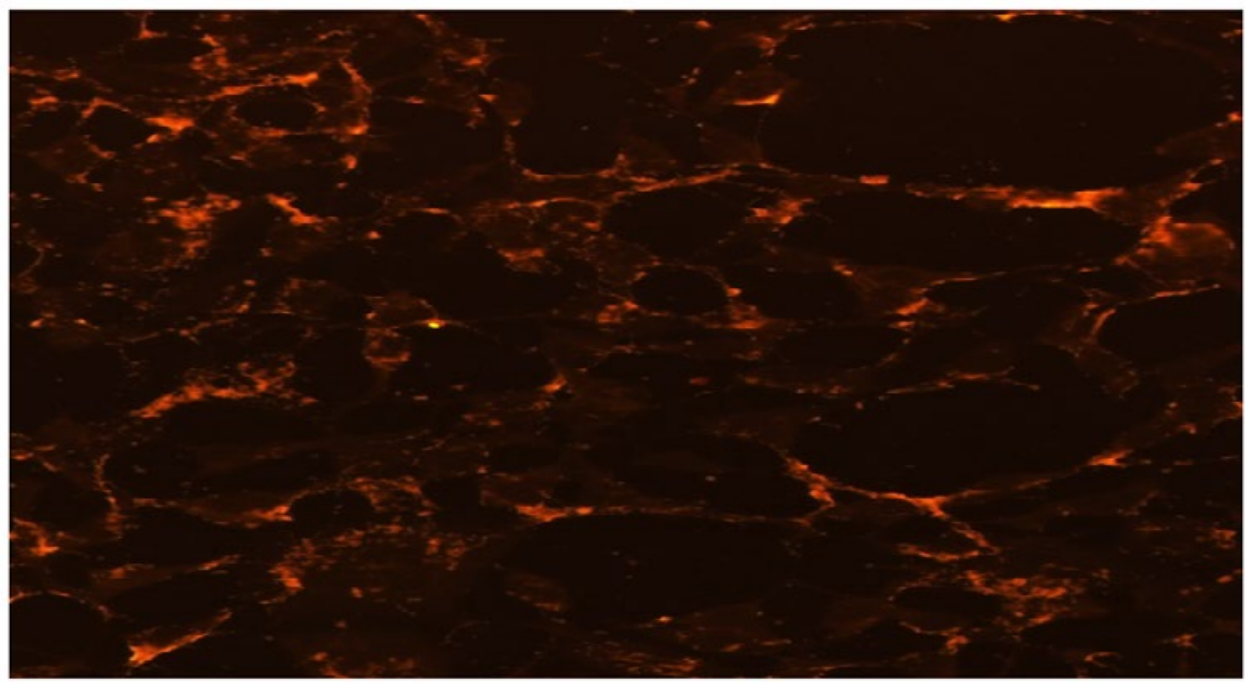

Figura 3. Colocalización de la proteína EGR-1. La rodamina acoplada al anticuerpo anti-EGR-1 humano mostró una ubicación citoplasmática y nuclear de fibroblastos expuestos a luz ultravioleta.

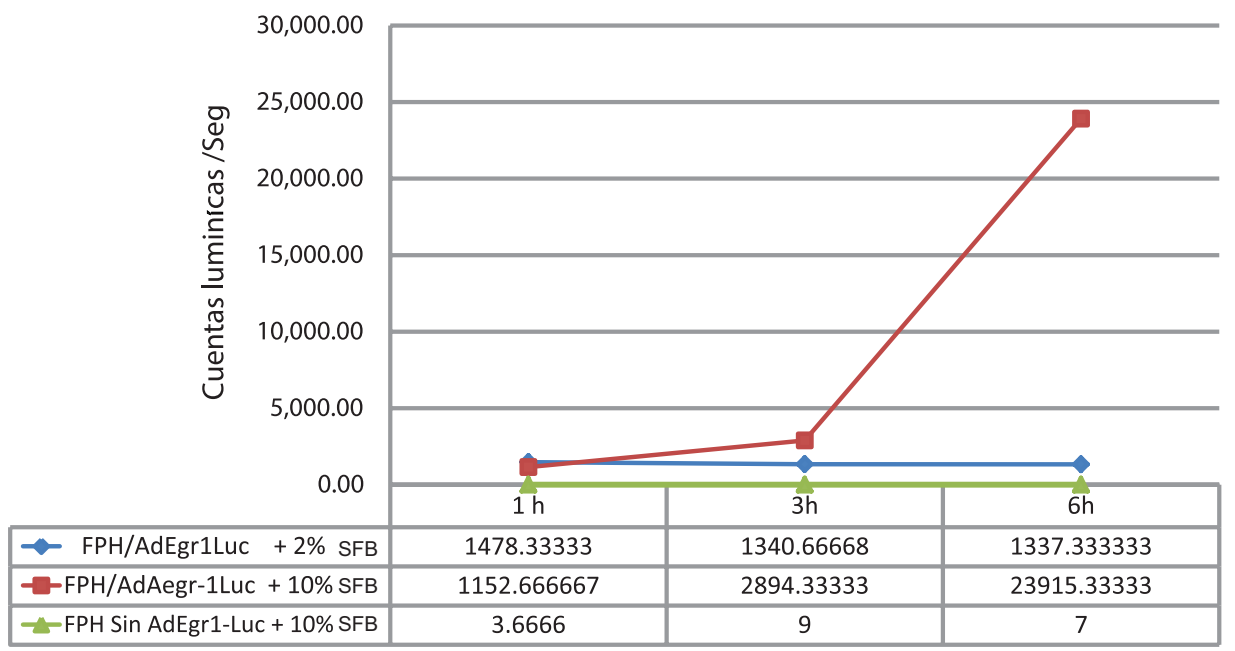

Figura 4. Actividad basal del promotor endógeno en fibroblastos primarios humanos (FPH). Para determinar el efecto de los inductores sobre la expresión de la proteína se documentó la presencia de la proteína EGR-1 en los FPH, y determinar su expresión como plataforma de la acción del sistema reportero. SFB: suero fetal bovino.

de $2189.66,2434.66$ y $3925.33 \mathrm{CL} / \mathrm{s}$ a los mismos tiempos.

\section{Efecto de las hormonas esteroides sobre el promotor en fibroblastos primarios humanos}

Las FPH fueron expuestas a testosterona y beta-estradiol para explorar el efecto de las hormonas esteroides sobre el promotor de EGR-1 en los fibroblastos transducidos. La testosterona mostró valores de 1353, 2720.66-2070.33 CL/s a las 1, 3 y 6 horas, respectivamente. El beta-estradiol mostró valores de 2189.662 ,
1434.66 y $3925.33 \mathrm{CL} / \mathrm{s}$ a las 1,3 y 6 horas, respectivamente.

\section{Efecto del EGF-1 sobre el promotor en fibroblastos primarios humanos}

Se observó un efecto regulador positivo en las células expuestas a EGF-1. Los extractos celulares mostraron un promedio de 29,511.33 CL/s a las 6 horas, con valores similares al control positivo (los FPH transducidas Ad-Egr-1/Luc7+ y expuestas a un $10 \%$ de SFB mostraron una lectura de 23,915.33 CL/s). 


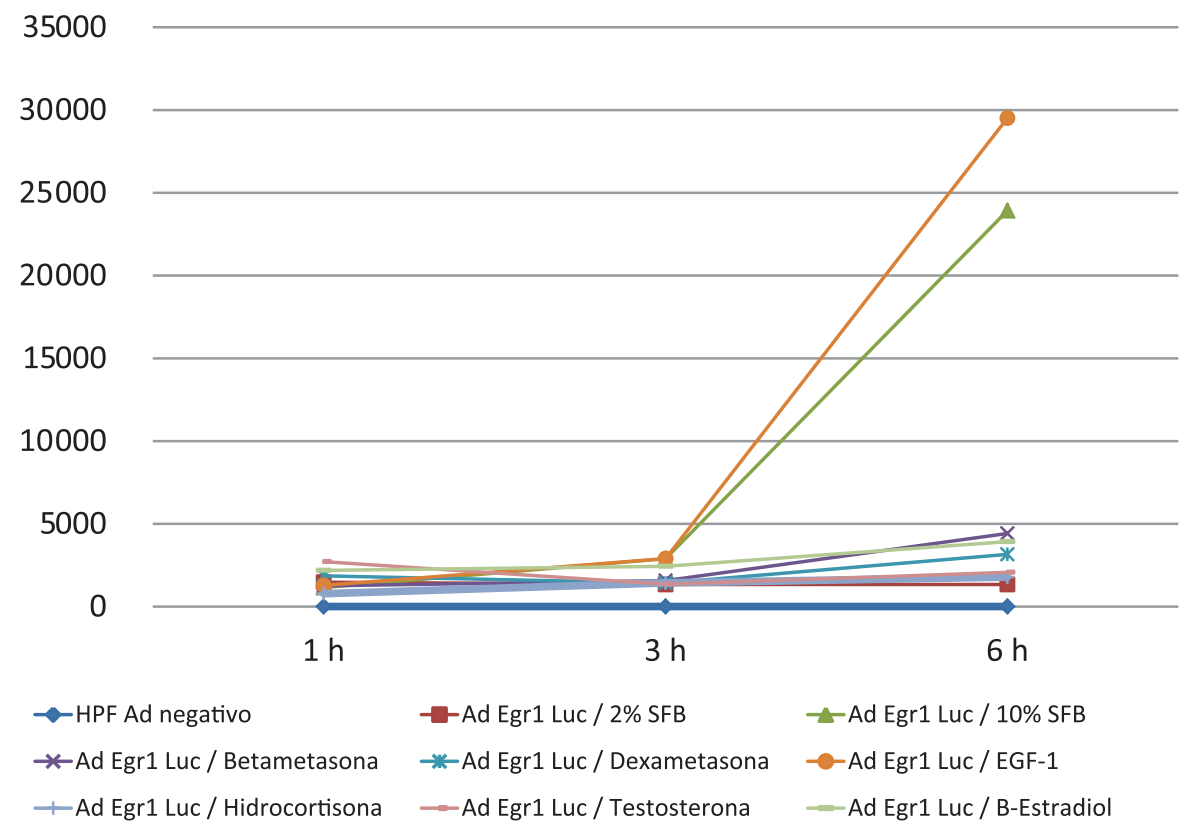

Figura 5. Efecto comparativo de fármacos esteroides sobre el promotor EGR-1 en fibroblastos humanos. El análisis cuantitativo de los extractos proteicos de las células transducidas y expuestas a los diferentes fármacos se resume en esta gráfica. La presencia de suero fetal bovino (SFB; 10\%) como activador de EGR-1 se usó como control positivo de inducción del promotor. La gráfica muestra el patrón de estimulación del factor de crecimiento epitelial 1 superior a la del SFB. Los otros fármacos esteroides probados mostraron una actividad menor o parecida a la actividad basal de la expresión en las células sometidas a depleción de SFB (2\%).

\section{Discusión y conclusiones}

La replicación celular es un elemento indispensable y esencial en los procesos de reparación tisular. En el caso de los pacientes con grandes pérdidas de tejido, tales como los grandes quemados, la proliferación celular es esencial para la granulación y la cicatrización de los tejidos lesionados. La proteína EGR-1 es esencial para inducir la expresión de los factores de crecimiento y de diferenciación, así como la activación de vías mitogénicas que promueven el reclutamiento, la diferenciación y la reparación tisular. Sin embargo, el disparo inicial de este mecanismo de expresión está abolido en las vías regulatorias autocrinas y paracrinas entre los queratinocitos, los fibroblastos y las células del folículo piloso ausentes en el paciente gran quemado. El uso de fármacos que permitan mantener estimulado este mecanismo, o la identificación de efectos regulatorios negativos, son esenciales para determinar la terapéutica farmacológica más eficiente para el paciente en estado agudo.

Los resultados obtenidos sugieren que el uso de esteroides como la betametasona y la hidrocortisona tiene efecto inhibitorio en la regulación génica a través del promotor de EGR-1, indicando que la hidrocortisona tiene el efecto inhibitorio más potente de todos los fármacos probados. Estos efectos no pueden concluirse como directos, pero permiten determinar el efecto biológico del promotor. También la testosterona y el beta-estradiol mostraron un patrón de crecimiento inhibitorio, con valores similares a los de las células en condiciones basales (FPH en Adegr- $1+$ con un $2 \%$ de SFB) (Fig. 5).

\section{EI EGF-1 regula positivamente al promotor de EGR-1}

De manera interesante, el EGF-1 regula positivamente la actividad del promotor. El incremento en la actividad de la luciferasa muestra un patrón similar en relación con el control positivo de células cultivadas en condiciones normales (Fig. 5). Este hallazgo permite continuar con estudios posteriores para usar el EGF-1 recombinante de manera local en pacientes grandes quemados y acelerar el proceso de recuperación clínica, controlado a su vez por los reguladores negativos que detengan este efecto después de concluir el proceso de reparación tisular (Fig. 6).

Aun cuando estos fármacos tienen la ventaja de estar aprobados para uso clínico, se requieren estudios mayores para explorar su efecto sobre la proliferación celular, así como un estudio de las vías mitogénicas involucradas, con objeto de explorar su interacción y utilidad clínica. 
ACTIVADOR:

$$
\begin{gathered}
\text { Luz UV } \\
\text { EGF-1 }
\end{gathered}
$$
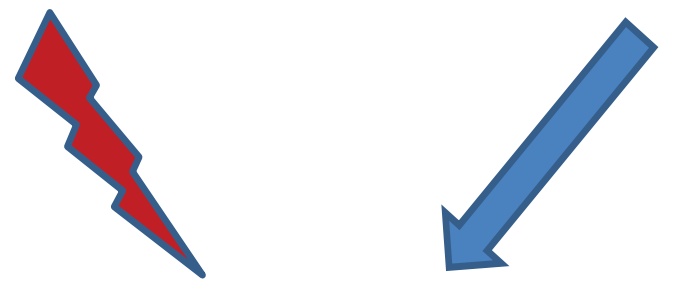

REPRESOR:

Betametasona

Hidrocortisona

Testosterona

B-Estradiol
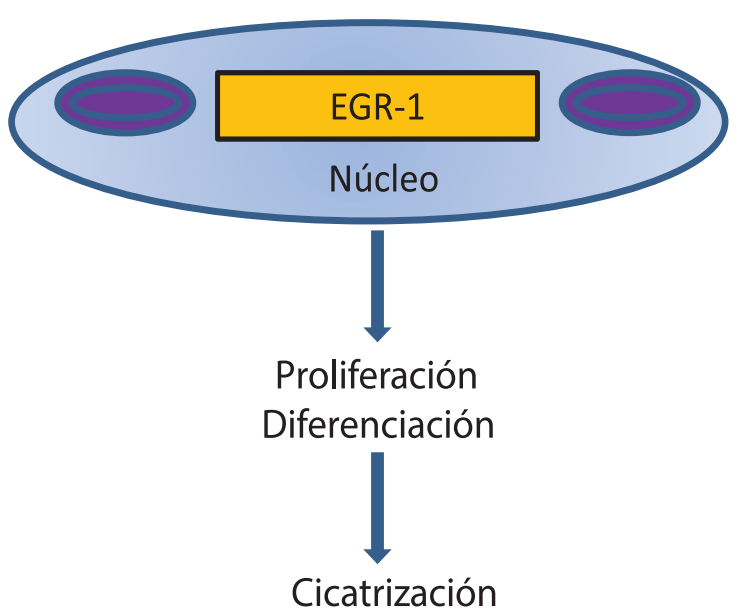

Figura 6. Modelo de regulación farmacológica del promotor EGR-1. Las células infectadas con el adenovirus Ad-Egr-1 Luc se exponen a luz ultravioleta y posteriormente se someten a un medio con $50 \mathrm{ng}$ de betametasona. Las células son lisadas para determinar la activación del gen reportero por cuantificación de la actividad lumínica.

\section{Agradecimientos}

Esta investigación fue apoyada por el Consejo Nacional de Ciencia y Tecnología (CONACyT) de México a través del proyecto Fossis-2011-161624.

Al Prof. Dr. Bert Vogelstein, de la Universidad Johns Hopkins, Baltimore, EE.UU., por donar amablemente el sistema de vector AdEasy1 usado para generar vectores adenovirales.

A la Dra. Kathleen Sakamoto, de la Escuela de Medicina de la Universidad de Stanford, EE.UU., por proporcionar el fragmento del promotor EGR-1.

In memoriam de la Prof. Acad. Dra. Hilda Villegas Castrejón, fundadora del Programa de Bioterapéutica Molecular en el Instituto Nacional de Rehabilitación Luis Guillermo Ibarra Ibarra, miembro de la Academia Mexicana de Cirugía, AC.

Este trabajo fue presentado en las actividades académicas de la Academia Mexicana de Cirugía y fue distinguido con la presea Acad. Dr. Gonzalo Castañeda en el año académico LXXXIII.

\section{Responsabilidades éticas}

Protección de personas y animales. Los autores declaran que para esta investigación no se han realizado experimentos en seres humanos ni en animales.

Confidencialidad de los datos. Los autores declaran que han seguido los protocolos de su centro de trabajo sobre la publicación de datos de pacientes.

Derecho a la privacidad y consentimiento informado. Los autores declaran que en este artículo no aparecen datos de pacientes.

\section{Conflicto de intereses}

Los autores declaran que no existen conflictos de intereses.

\section{Bibliografía}

1. Sukhatme VP. Early transcriptional events in cell growth: the Egr family. J Am Soc Nephrol. 1990;1:859-66. 
2. Zwang $Y$, Sas-Chen A, Drier $Y$, Shay $T$, Avraham R, Lauriola M, et al. Two phases of mitogenic signaling unveil roles for p53 and EGR1 in elimination of inconsistent growth signals. Mol Cell. 2011;42:524-35.

3. Sakamoto KM, Fraser JK, Lee HJ, Lehman E, Gasson JC. Granulocyte macrophage colony-stimulating factor and interleukin-3 signaling pathways converge on the CREB-binding site in the human egr-1 promoter. Mol Cell Biol. 1994;14:5975-85.

4. Sakamoto KM, Bardeleben C, Yates KE, Raines MA, Golde DW Gasson JC. 5' upstream sequence and genomic structure of the human primary response gene, EGR-1/TIS8. Oncogene. 1991;6:867-71.

5. Aicher WK, Sakamoto KM, Hack A, Eibel H. Analysis of functional elements in the human Egr-1 gene promoter. Rheumatol Int. 1999:18:207-14.

6. Schwachtgen JL, Campbell CJ, Braddock M. Full promoter sequence of human early growth response factor-1 (Egr-1): demonstration of a fifth functional serum response element. DNA Seq. 2000;10:429-32.

7. Rolli M, Kotlyarov A, Sakamoto KM, Gaestel M, Neininger A. Stress-induced stimulation of early growth response gene- 1 by p38/stress-activated protein kinase 2 is mediated by a cAMP-responsive promoter element in a MAPKAP kinase 2-independent manner. J Biol Chem. 1999;274: 19559-64.

8. Mora-Garcia P, Sakamoto KM. Granulocyte colony-stimulating factor induces Egr-1 up-regulation through interaction of serum response element-binding proteins. J Biol Chem. 2000;275:22418-26.

9. Huang RP, Fan Y, Boynton AL. UV irradiation upregulates Egr-1 expression at transcription level. J Cell Biochem. 1999;73:227-36.

10. Martínez-Flores F, Machuca-Rodríguez C, Sandoval-Zamora $\mathrm{H}$, Aguirre-Cruz L, Valdez-Flores M, Villegas-Castrejón H. Steroid drugs and GM-CSF modulates activity of EGR-1 in glioma cells. Cir Cir. 2013;81: 3-13.

11. Pritchard MT, Malinak RN, Nagy LE. Early growth response (EGR)-1 is required for timely cell-cycle entry and progression in hepatocytes after acute carbon tetrachloride exposure in mice. Am J Physiol Gastrointest Liver Physiol. 2011;300:G1124-31.

12. He TC, Zhou S, da Costa LT, Yu J, Kinzler KW, Vogelstein B. A simplified system for generating recombinant adenoviruses. Proc Natl Acad Sci USA. 1998;95:2509-14.
13. Martínez-Flores F, Jiménez-Orozco FA, Villegas-Castrejón H. Molecular biology of adenoviral vectors. Cir Cir. 2006;74:483-93.

14. Hsu H, Rainov NG, Quinones A, Eling DJ, Sakamoto KM, Spear MA. Combined radiation and cytochrome CYP4B1/4-ipomeanol gene therapy using the EGR1 promoter. Anticancer Res. 2003;23:2723-8.

15. Ernst A, Aigner M, Nakata S, Engel F, Schlotter M, Kloor M, et al. A gene signature distinguishing CD133hi from CD133-colorectal cancer cells: essential role for EGR1 and downstream factors. Pathology. 2011;43: 220-7.

16. Neuhaus T, Stier S, Totzke G, Gruenewald E, Fronhoffs S, Sachinidis A, et al. Stromal cell-derived factor 1alpha (SDF-1alpha) induces gene-expression of early growth response-1 (Egr-1) and VEGF in human arterial endothelial cells and enhances VEGF induced cell proliferation. Cell Prolif. 2003;36:75-86.

17. Perogamvros I, Ray DW, Trainer PJ. Regulation of cortisol bioavailability effects on hormone measurement and action. Nat Rev Endocrinol 2012;8:717-27.

18. Stahn C, Löwenberg M, Hommes DW, Buttgereit F. Molecular mechanisms of glucocorticoid action and selective glucocorticoid receptor agonists. Mol Cell Endocrinol. 2007;275:71-8.

19. Pezzoli D, Chiesa R, De Nardo L, Candiani G. We still have a long way to go to effectively deliver genes! J Appl Biomater Function Mater. 2012;27;10:e82-91.

20. Runge-Morris M, Rose K, Kokarec TA. Regulation of rat hepatic sulfotransferase gene expression by glucocorticoid hormones. Drug Metab Dispos. 1996;24:1095-101.

21. Shin SY, Kim JH, Baker A, Lim Y, Lee YH. Transcription factor Egr-1 is essential for maximal matrix metalloproteinase-9 transcription by tumor necrosis factor alpha. Mol Cancer Res. 2010;8:507-19.

22. Tiganescu A, Tahrani AA, Morgan SA, Otranto $M$, Desmoulière A, Abrahams $L$, et al. 11 $\beta$-Hydroxysteroid dehydrogenase blockade prevents age-induced skin structure and function defects. J Clin Invest. 2013;123:3051-3060.

23. Werth BB, Bashir M, Chang L, Werth VP. Ultraviolet irradiation induces the accumulation of chondroitin sulfate, but not other glycosaminoglycans, in human skin. PLoS One. 2011;6:e14830. 